\title{
Prevalence, associated factors, and relationship to quality of life of lower urinary tract symptoms: a cross- sectional, questionnaire survey of cancer patients
}

\author{
C.-I. Hsieh, ${ }^{1,2}$ A.-L. Lung, ${ }^{3}$ L.-I. Chang, ${ }^{4}$ C. M. Sampselle, ${ }^{5}$ C.-C. Lin, ${ }^{6}$ Y.-M. Liao ${ }^{7}$
}

'Department of Internal

Medicine, College of Medicine, Taipei Medical University

${ }^{2}$ Division of Hematology and Oncology, Department of

Internal Medicine, Taipei

Medical University Hospital,

Taipei, Taiwan

${ }^{3}$ Department of Nursing, Armed

Forces TaoYuan General

Hospital, TaoYuan County,

Taiwan

${ }^{4}$ Graduate Institute of Nursing,

College of Nursing, Taipei

Medical University, Taipei,

Taiwan

${ }^{5}$ School of Nursing, University

of Michigan, Ann Arbor, MI,

USA

${ }^{6}$ School of Nursing, College of

Nursing, Taipei Medical

University, Taipei, Taiwan

${ }^{7}$ Graduate Institute of Nursing,

College of Nursing, Taipei

Medical University, Taipei,

Taiwan

Correspondence to:

Yuan-Mei Liao

Graduate Institute of Nursing, College of Nursing, Taipei

Medical University, 250 Wu-

Xing Street, Taipei 110, Taiwan

Tel.: 886227361661 (ext

6312)

Fax: 886223772842

Email:ymliao@tmu.edu.tw

Disclosures

The authors have no conflicts

of interest to declare.

\section{SUMMARY}

Background: Few studies conducted outside of Asia have shown that lower urinary tract symptoms (LUTS) could be a concern for cancer patients. This gap necessitates more research on LUTS among cancer patients in Asia, particularly regarding associated factors and the relationship between quality of life and LUTS. Objectives: This study investigates the prevalence, associated factors, and relationship to quality of life of LUTS based on a sample of cancer patients. Design: A cross-sectional, questionnaire survey. Settings/participants: This study was conducted at two oncology outpatient departments in two hospitals in Taiwan, and included 134 Asian cancer patients. Methods: We collected information about each participant's individual characteristics, personal habits, LUTS, and quality of life by using a questionnaire. We calculated descriptive statistics to demonstrate the distribution of collected information, and used multivariate logistic regression to identify the factors associated with LUTS. We used Student's t-test to compare the mean quality of life scores for participants with and without LUTS. Results: Ninety-nine (73.9\%) participants experienced at least one type of LUTS, and the prevalence rates for various types of LUTS ranged from $3.7 \%$ to $52.2 \%$. Radiotherapy and the time since the diagnosis of cancer were associated with LUTS. Participants with LUTS reported lower quality of life scores than participants without LUTS. Conclusions: The high prevalence of LUTS suggests that cancer treatment might be linked to LUTS, which in turn has a negative effect on a patient's quality of life. These results suggest that future research should involve studies in larger, more homogeneous samples. Health care providers should monitor the presence of LUTS and deliver the management and treatments of LUTS to optimise cancer patients' quality of life.

\section{Background}

Cancer patients frequently experience multiple symptoms concurrently. Most cancer patients experience more (3-18) concurrent symptoms than patients with other chronic diseases (1). These symptoms are major problems for cancer patients, health care providers, and family caregivers. Unrelieved symptoms have negative effects on patients' health conditions and health-related quality of life (HRQL) (2).

Forty-five percent of cancer survivors $(n=321)$ reported that urinary incontinence (UI) might be attributed to cancer (3). Alfano et al. (4) found that $46-58 \%$ of breast cancer patients $(n=803)$ experienced difficulty with bladder control. Gift et al. (5) reported that $15 \%$ of lung cancer patients $(n=220)$

\section{What's known}

Few studies conducted outside of Asia have shown that lower urinary tract symptoms (LUTS) could be a concern for cancer patients, and few of these studies have investigated LUTS among Asian cancer patients. Previous research on LUTS among cancer patients is limited, particularly regarding the associated factors and relationship to the quality of life.

\section{What's new}

The prevalence of LUTS among cancer patients is high. Radiotherapy and the time since the diagnosis of cancer might be linked to LUTS. Cancer patients with LUTS reported lower quality of life scores than those without symptoms. These results contribute to knowledge about LUTS among Asian cancer patients. experienced urinary problems, and 68\% indicated getting up at night to urinate. These findings suggest that lower urinary tract symptoms (LUTS) could be a concern for cancer patients (3-5). However, few studies on LUTS among cancer patients involve nonAsian populations, and information on LUTS among Asian cancer patients is lacking.

Storage, voiding, and post-micturition are the three main symptom groups of LUTS. Storage symptoms, which occur during the filling and storage phase of the bladder, include increased daytime urinary frequency, nocturia, urinary urgency, and UI. Voiding symptoms, such as slow stream, splitting or spraying, intermittent stream, hesitancy, straining, and terminal dribble, occur during the voiding phase. Post-micturition symptoms, including a feel- 
ing of incomplete emptying and post-micturition dribble, occur immediately after micturition (6). The prevalence of LUTS ranges from $48 \%$ to $64 \%$ among the general population (7-9). The high prevalence of LUTS among the general population warrants special attention to these relatively neglected symptoms among cancer patients.

People without LUTS have better HRQL and physical/mental health than people with LUTS $(10,11)$, and symptom severity is negatively associated with HRQL and sleep (12,13). Although LUTS have widespread human and psychosocial implications that negatively affect HRQL $(10,11)$, only onefourth to one-third of people with LUTS seek professional help $(14,15)$. Previous studies have shown that sleep disturbances are common in cancer patients $(5,16,17)$. Cancer patients who received treatment (e.g. chemotherapy, radiotherapy, and surgery) in the previous 6 months have more sleep disturbances than those who did not (16). Other research has shown an association between LUTS and sleep disturbances (13), and further research is needed to examine this association in cancer patients.

Research on LUTS among cancer patients is limited, particularly regarding associated factors and the relationship between HRQL and LUTS. Therefore, this study investigates the prevalence, associated factors, and relationship to HRQL of LUTS among cancer patients. The results of this study contribute to knowledge about LUTS among Asian cancer patients. This study is important to cancer patients because it increases the awareness of this common health concern, and opens channels of communication among cancer patients with LUTS and among oncology health care providers.

\section{Methods}

\section{Study design and ethical approval}

This study is a cross-sectional, questionnaire survey. We conducted a pilot study before the main study. The pilot study was conducted to obtain feedback from cancer patients on possible problem areas (e.g. difficulty of interpreting terms or statements) in the questionnaire. The pilot study also confirmed the adequacy of the data collection process. Ethical approval was obtained from two selected hospitals before the study commenced.

\section{Setting and sample}

This study was conducted at two oncology outpatient departments in two hospitals in Taiwan. The outpatient departments participating in this study assigned a number to each qualified patient, and generated two sampling lists and a systematic sampling method to select every third patient listed. If the selected patient refused to participate, no patient was recruited as a substitute. Inclusion criteria included a confirmed diagnosis of certain cancers for 6 months to 5 years, age equal or more than 18 years, cognitive clarity, ability to communicate, and awareness of cancer diagnosis. We excluded patients with prostate cancer because information on LUTS is already available for this population. Other exclusion criteria included (1) major cognitive impairment or inability to provide informed consent, and (2) severe physical weakness to tolerate an interview of 20-30 min.

The main study consisted of interviews with 140 cancer patients. We excluded questionnaires completed by cancer patients who currently experienced burning during urination $(n=6)$ from analysis because they might have experienced a urinary tract infection (UTI) at the time of data collection. We used the information collected from 134 cancer patients for data analysis.

\section{Measures}

The questionnaire in this study included four sections covering various areas: (1) individual characteristics, (2) personal habits, (3) LUTS, and (4) HRQL. The majority of items in two sections (individual characteristics and personal habits) were derived from the Taiwan Teacher Bladder Survey (TTBS) (18). The LUTS items in the study questionnaire were the same as the LUTS items in the TTBS. We used the Short-Form 36 Health Survey (SF-36), Taiwan version, to measure HRQL.

The internal consistency of the LUTS construct, content validity, and the test-retest reliability of the TTBS were adequate (18). For generating the study questionnaire, we modified the items in the TTBS to reduce the interview duration. First, we eliminated some items related to teachers' working experience/ employment setting, and some conditions (e.g. pregnancy) that would be uncommon among cancer patients. Second, we added items about patient sex and disease (primary cancer site, cancer stage, time since the diagnosis of cancer, treatments received, and treatment status). Third, any items related to frequency and duration of LUTS became the subitems of the item indicating the presence of LUTS. Patients who did not experience certain types of LUTS could skip the related sub-items. For example, participants who did not experience UI could skip the sub-items related to the frequency and duration of UI. Fourth, we added one item related to sleep because sleep disturbances might be linked to LUTS (13). The final questionnaire included 40 items: individual characteristics (18 items), personal habits (8 items), LUTS including UTI (10 items), LUTS- 
related disturbances (two items), and help-seeking behaviour (two items).

Six experts (two oncologists, one oncology nurse, and three cancer patients) were invited to review the content validity of the study questionnaire. These experts graded each item based on the precision of the statement/response options and the appropriateness to the research aims of this study. We confirmed the grade system and criterion for ensuring content validity based on the standard proposed by Lynn (19). The 6 experts confirmed the content validity of the study questionnaire. Thirty participants in the pilot study did not report any specific problems with the study questionnaire or the data collection process. This pilot study confirmed the adequacy of the data collection process and helped streamline the study procedure.

We collected information on the participants' sex, age, body height/weight, disease and health-related conditions (e.g. history of diabetes mellitus). For personal habits, we collected information on individual smoking habits, bladder habits, and habits of fluid and caffeine consumption. The classification methods used for categorising each participant's individual characteristics and personal habits were the same as those used in a previous study (20). We categorised participants' bladder habits and fluid consumption habits into two levels (good or poor) based on their responses to items related to delaying urination, restricting hydration, and the likelihood of adequate hydration. Each participant's cancer stage was confirmed by his or her primary oncologist(s) using the labels of Stage I, II, III, or IV to represent the cancer stage. Each stage was based on the TNM staging system developed and maintained by the American Joint Committee on Cancer (21). Treatments received included chemotherapy or target therapy, surgery, radiotherapy, and endocrine therapy. Treatment status included 3 categories: active treatment (e.g. chemotherapy/target therapy, surgery, radiotherapy, or endocrine therapy), post-treatment for less than 6 months, and post-treatment for more than 6 months.

This study defines the presence of 8 different LUTS as follows: self-reported occurrence of UI, increased daytime urinary frequency, urinary urgency, nocturia, intermittent stream, weak urinary stream, hesitancy, and a feeling of incomplete emptying during the past 6 months. These LUTS were chosen because they facilitate the comparisons between the findings reported in the literature (7-9) and the results reported in the current study. We collected information about UTI to exclude patients who might experience UTI at the time of data collection because several LUTS (e.g. UI, urinary frequency, and urinary urgency) are associated with UTI. Most definitions of individual LUTS used in this study are based on a standardisation report proposed by the International Continence Society $(6,22)$. A related study has reported all of these definitions of individual LUTS (23). This study defines the presence of LUTS as the LUTS occurring at least one or several times a month and lasting more than 1 month.

The SF-36 is scored from 0 to 100 , with a higher number representing a better HRQL $(24,25)$. The SF36 includes 36 items, and has been widely used in the medical literature to measure physical and mental HRQL. Specific HRQL aspects may be ascertained using eight separate domains, which are physical functioning, role limitation caused by physical health problems, bodily pain, general health, vitality, social functioning, role limitation caused by emotional problems, and mental health. We computed two summary scores, the physical component summary (PCS) and mental component summary (MCS), using regression weights derived from principal component factor analysis. The PCS and MCS scales summarise the $8 \mathrm{HRQL}$ aspect scores into two summary scores that give an overall assessment of the quality of life related to physical and mental health, respectively $(24,25)$. Reliability and validity tests of the SF-36 Taiwan version satisfied most conventional psychometric criteria (26-28), and we obtained approval to use the SF-36 Taiwan version.

\section{Procedure}

In the pilot study, a research nurse trained by the principal investigator interviewed 30 cancer patients at one selected hospital. Participants were interviewed (20-30 $\mathrm{min})$ in a private area at the outpatient department. The research nurse extracted the patients' disease-related information (e.g. cancer diagnosis and received treatment) from their medical records. The research nurse also measured the patient's body height/weight, recorded the participant's responses, and collected information using the study questionnaire. Each participant received a copy of the informed consent letter, a questionnaire, and a gift of US\$10. The main study used a data collection procedure similar to that of the pilot study. The period of data collection for the main study was 18 months.

\section{Data analysis}

We used IBM sPss Statistics for Windows (IBM Corporation, Armonk, NY, USA) to analyse the data. A p-value of less than .05 was regarded as statistically significant. Descriptive statistics were calculated to demonstrate the prevalence of LUTS and the distributions of participants' individual characteristics, personal habits, and HRQL. We used chi-squared 
tests to compare the prevalence of LUTS for patients with various characteristics, and adopted multivariate logistic regression (backward elimination model) to identify factors associated with LUTS. The variable selection procedure, based on the process proposed by Hosmer and Lemeshow (29), began with univariate analyses of each independent variable. Any variable with a univariable chi-squared test that had a pvalue of less than .25 was a candidate for the multivariable model. After identifying all significant predictors $(\mathrm{p}<.05)$ for LUTS, we examined the effects of the first-order interactions (29). The final model obtained estimated odds ratios and associated 95\% confidence intervals (CI) for the presence of LUTS for each independent variable while controlling for the other independent variables. Student $t$-tests were used to compare the mean scores of the PCS, MCS, and $8 \mathrm{HRQL}$ aspects in the SF-36 for participants with and without LUTS.

\section{Results}

All participants in this study were native Taiwanese. Most of the cancer patients were women $(n=77$, $57.5 \%)$, more than 45 years of age $(n=119,88.8 \%)$, and had a normal body mass index $(n=85,63.4 \%)$ (Table 1). Table 2 shows the distribution of participants' personal habits. Most participants had good bladder habits and fluid consumption habits.

Of the 134 participants, 99 (73.9\%) experienced at least one type of LUTS. The prevalence of different LUTS ranged from $3.7 \%$ (hesitancy) to $52.2 \%$ (nocturia). Participants were more likely to experience storage symptoms than voiding or post-micturition symptoms. Table 3 shows the prevalence of LUTS for different cancer diagnoses. The prevalence of any LUTS in lung cancer patients was lower than the rates in patients with other types of cancer.

We did not conduct data analyses separately based on a participant's treatment status because the prevalence of LUTS for cancer patients under active treatment $(n=58,72.5 \%)$, post-treatment less than 6 months $(n=21,70.0 \%)$, and post-treatment more than 6 months $(n=20,83.3 \%)$ was not statistically significantly different $(p=.491)$, and the three groups had few participants. The results of the chisquared tests showed that (1) participants who received radiotherapy $(n=35,85.4 \%)$ were more likely to experience LUTS than those who did not $(n=64,68.8 \%)(\mathrm{p}=.044)$, and (2) participants who were diagnosed with cancer for more than 18 months $(n=49,86.0 \%)$ were more likely to experience LUTS than those who were diagnosed with cancer for less than 18 months $(n=50,64.9 \%)$ $(\mathrm{p}=.006)$.
The multivariate logistic regression model in this study identified two factors associated with LUTS. Participants who received radiotherapy had 3.0 times $(\mathrm{p}=.033,95 \% \mathrm{CI}=1.0,8.0)$ higher odds of experiencing LUTS than those who did not receive radiotherapy. Participants diagnosed with cancer for more than 18 months had 3.6 times $(\mathrm{p}=.005,95 \%$ $\mathrm{CI}=1.5$, 8.8) higher odds of experiencing LUTS than those who were diagnosed with cancer for less than 18 months. The final model showed no interaction effect.

Table 4 presents information about the norms of the SF-36 for Taiwanese ages 12 years and above (28). Participants without LUTS reported higher mean scores of HRQL (PCS, MCS, and 5 HRQL aspects in the SF-36) than participants with LUTS. Eight HRQL scores for all participants (with or without LUTS) were all below the norms for Taiwanese, indicating below-average HRQL. The mean scores of HRQL were significantly different for participants with and without LUTS on two HRQL aspects: physical functioning and role limitation caused by physical health problems (Table 4). Participants with LUTS reported mild to moderate LUTS-related irritations in their daily lives $(n=44,44.4 \%)$ and sleep ( $n=46,46.5 \%)$. Only $17(17.2 \%)$ of participants with LUTS had mentioned their LUTS to health care providers.

\section{Discussion}

\section{Prevalence of LUTS}

This study uses 3 population-based studies on LUTS in men and women to compare with the current results (7-9). In these studies, the prevalence of LUTS ranged from $61 \%$ to $64 \%(8,9)$. Storage LUTS were more prevalent than voiding or post-micturition LUTS $(8,9)$, and nocturia ( $\geq 1$ episode/night) was the most common LUTS (37-76\%) (7-9). A more restrained definition of nocturia ( $\geq 2$ episodes/ night) yielded a lower prevalence: the prevalence of LUTS decreased to $47-48 \%$ (8), and the prevalence of nocturia decreased to $10-34 \%$ (7-9). Other population-based studies were excluded from comparison because they used different LUTS classification methods (11,31), were conducted among a single sex $(30,31) /$ a specific age group $(32,33)$, or did not report the prevalence of individual LUTS $(34,35)$.

This study shows that storage is the most common group of LUTS, and nocturia is the most prevalent symptom. These findings are consistent with the reported prevalence patterns in previous research (79). However, the prevalence of any LUTS (73.9\%) and nocturia $(52.2 \%)$ was higher than the rates reported in earlier studies $(8,9)$. The age of partici- 


\begin{tabular}{|c|c|c|}
\hline Variables & $\mathbf{n}$ & $\%$ \\
\hline \multicolumn{3}{|l|}{ Sex } \\
\hline Female & 77 & 57.5 \\
\hline Male & 57 & 42.5 \\
\hline \multicolumn{3}{|c|}{ Age (Range: $27-92$, Mean $=60.6, S D=13.1)$} \\
\hline$\leqq 45$ & 15 & 11.2 \\
\hline $46-55$ & 30 & 22.4 \\
\hline $56-65$ & 39 & 29.1 \\
\hline$>65$ & 50 & 37.3 \\
\hline \multicolumn{3}{|c|}{$\begin{array}{l}\text { Body mass index (Range: } 15.6-38.3, \text { Mean }=23.5, \\
\text { SD }=3.8 \text { ) }\end{array}$} \\
\hline$<18.5$ underweight & 9 & 6.7 \\
\hline $18.5-24.9$ normal & 85 & 63.4 \\
\hline$\geqq 25$ overweight & 40 & 29.9 \\
\hline \multicolumn{3}{|l|}{ Marital status } \\
\hline Married & 107 & 79.9 \\
\hline Single (separated, divorced, or widowed) & 19 & 14.2 \\
\hline Single, never married & 8 & 5.9 \\
\hline \multicolumn{3}{|l|}{ Primary cancer site } \\
\hline Breast & 39 & 29.1 \\
\hline Lung & 30 & 22.4 \\
\hline Colorectal & 17 & 12.7 \\
\hline $\begin{array}{l}\text { Female genital system } \\
\text { [cervical (9), and ovarian (2)] }\end{array}$ & 11 & 8.2 \\
\hline $\begin{array}{l}\text { Other [oesophagus (8), } \\
\text { lymphoma (6), stomach (6), } \\
\text { bladder (6), thymus gland (4), } \\
\text { thyroid (3), pancreas (3), liver (1)] }\end{array}$ & 37 & 27.6 \\
\hline \multicolumn{3}{|l|}{ Cancer stage } \\
\hline । & 16 & 11.9 \\
\hline ॥ & 51 & 38.1 \\
\hline III & 42 & 31.3 \\
\hline IV & 25 & 18.7 \\
\hline \multicolumn{3}{|l|}{ Time since diagnosis of cancer } \\
\hline 6 months-18 months & 77 & 57.5 \\
\hline 18 months -3 years & 46 & 34.3 \\
\hline 3 years -5 years & 11 & 8.2 \\
\hline \multicolumn{3}{|l|}{ Treatment(s) received } \\
\hline Chemotherapy or target therapy + surgery & 51 & 38.1 \\
\hline $\begin{array}{l}\text { Radiotherapy + chemotherapy } \\
\text { or target therapy + surgery }\end{array}$ & 29 & 21.6 \\
\hline Chemotherapy or target therapy & 24 & 17.9 \\
\hline Surgery & 16 & 11.9 \\
\hline $\begin{array}{l}\text { Radiotherapy + chemotherapy or } \\
\text { target therapy }\end{array}$ & 12 & 9.0 \\
\hline Endocrine therapy + surgery & 2 & 1.5 \\
\hline \multicolumn{3}{|l|}{ Treatment status } \\
\hline Active treatment & 80 & 59.7 \\
\hline Post-treatment $\leqq 6$ months & 30 & 22.4 \\
\hline Post-treatment $>6$ months & 24 & 17.9 \\
\hline \multicolumn{3}{|l|}{ Other chronic disease } \\
\hline Yes & 22 & 16.4 \\
\hline Diabetes & $(18)$ & $(13.4)$ \\
\hline Neurologic disorders & (3) & $(2.2)$ \\
\hline Diabetes and neurologic disorders & (1) & (0.8) \\
\hline No & 112 & 83.6 \\
\hline
\end{tabular}

\begin{tabular}{lll|}
\hline Table 1 Continued & & \\
\hline Variables & $\mathbf{n}$ & $\%$ \\
\hline Chronic constipation & & \\
$\quad$ Yes & 36 & 26.9 \\
$\quad$ No & 98 & 73.1 \\
Chronic cough & & \\
$\quad$ Yes & 36 & 26.9 \\
$\quad$ No & 98 & 73.1 \\
Abdominal or spinal surgery & & \\
$\quad$ Yes & 78 & 58.2 \\
$\quad$ No & 56 & 41.8 \\
\hline
\end{tabular}

pants might explain the high prevalence in this study because LUTS increase with age $(8,36,37)$. Study results show significant associations between LUTS and anxiety/depression (10), and LUTS severity and sleep disturbance severity (13). Chronic anxiety, depression, and sleep disorders are the main factors associated with LUTS $(36,37)$. The possibility of neurochemical changes in the central nervous system (CNS) that could predispose a patient to depression also influences the autonomic neural activity regulating the urinary tract (37). Klausner and Steers (38) proposed that corticotrophin-releasing factor is expressed in the areas of the CNS that control voiding and response to stress. This corticotrophin-releasing factor also increases during anxiety, depression, and pain. Thus, possible associations between LUTS and these conditions cannot be excluded because these conditions are common among cancer patients (39-41). A high prevalence of LUTS supports the need for appropriate pain, mental health, and sleep disturbance assessments when LUTS are present.

\section{Individual LUTS}

The prevalence of most individual LUTS in this study is higher than that reported in two studies (participant age $\geq 18$ years) $(8,9)$, and similar to or lower than the rates reported in another study (participant age $\geq 40$ years, and frequency of LUTS at least sometimes) (7). The prevalence of weak urinary stream is similar to that reported in the Lee et al. study (9), and the prevalence of some individual LUTS (e.g. urgency or incomplete emptying) is similar to the rates found in those aged $\geq 60$ years (8). These discrepancies might be the result of different sample characteristics or data collection methods, making a direct comparison with this study difficult.

The high prevalence of nocturia warrants special attention. Potential factors underlying nocturia include reduced bladder capacity, sleep disorders, 24-h polyuria, and nocturnal polyuria (42). For example, detrusor over-activity and bladder hypersensitivity are 


\begin{tabular}{|c|c|c|}
\hline Variables & $\mathbf{n}$ & $\%$ \\
\hline \multicolumn{3}{|l|}{ Smoking habit } \\
\hline Yes & 6 & 4.5 \\
\hline No & 128 & 95.5 \\
\hline \multicolumn{3}{|l|}{ Bladder habit } \\
\hline Good & 129 & 96.3 \\
\hline Poor & 5 & 3.7 \\
\hline \multicolumn{3}{|l|}{ Delay urinating } \\
\hline Never & 83 & 61.9 \\
\hline Sometimes (1 day a week or less) & 35 & 26.1 \\
\hline Usually (2 or 3 days a week) & 13 & 9.7 \\
\hline Always (every day or nearly every day) & 3 & 2.2 \\
\hline \multicolumn{3}{|c|}{$\begin{array}{l}\text { Reduce fluid consumption to prolong urination interval } \\
\text { or to avoid urination }\end{array}$} \\
\hline Never & 101 & 75.4 \\
\hline Sometimes (1 day a week or less) & 24 & 17.9 \\
\hline Usually (2 or 3 days a week) & 5 & 3.7 \\
\hline Always (every day or nearly every day) & 4 & 3.0 \\
\hline \multicolumn{3}{|l|}{ Fluid consumption habit } \\
\hline Good & 119 & 88.8 \\
\hline Poor & 15 & 11.2 \\
\hline \multicolumn{3}{|l|}{ Did not drink fluid until thirsty } \\
\hline Never & 65 & 48.5 \\
\hline Sometimes (1 day a week or less) & 21 & 15.7 \\
\hline Usually (2 or 3 days a week) & 19 & 14.2 \\
\hline Always (every day or nearly every day) & 29 & 21.6 \\
\hline \multicolumn{3}{|c|}{ Ignored fluid consumption because of discomfort } \\
\hline Never & 109 & 81.3 \\
\hline Sometimes (1 day a week or less) & 16 & 11.9 \\
\hline Usually ( 2 or 3 days a week) & 9 & 6.7 \\
\hline Always (every day or nearly every day) & 0 & 0 \\
\hline \multicolumn{3}{|l|}{ Fluid intake (ml/day) } \\
\hline$<1500 \mathrm{ml} / \mathrm{day}$ & 77 & 57.5 \\
\hline 1500-3000 ml/day & 51 & 38.1 \\
\hline$>3000 \mathrm{ml} /$ day & 6 & 4.4 \\
\hline \multicolumn{3}{|l|}{ Caffeine consumption } \\
\hline Yes & 44 & 32.8 \\
\hline No & 90 & 67.2 \\
\hline
\end{tabular}

related to bladder storage, and excessive evening intake of fluid/caffeine and oestrogen deficiency are related to nocturnal polyuria (42). Further studies should investigate the possible causes of nocturia in cancer patients by obtaining information from a voiding diary, urodynamics analysis, or a sleep laboratory. Nocturia has a wide range of negative consequences, including sleep disturbance, mood disturbance, poor overall health, reduced HRQL, and increased falls and fractures (43). Health care providers should be aware that cancer patients may be affected by nocturia, and offer appropriate management or treatments.

\section{LUTS in various types of cancer}

A recent systematic review of 16 studies suggested that urinary symptoms are prevalent among breast cancer patients (44). The results of the current study support this conclusion. Breast cancer occurs primarily in women around menopause, and ovarian suppression or failure after chemotherapy is related to early menopause (44). Hormone-related symptoms, such as vasomotor and urogenital symptoms, are prevalent after chemotherapy or endocrine therapy in breast cancer patients $(45,46)$. When women are diagnosed with breast cancer, they typically cease their hormone replacement therapy, which may intensify the menopausal symptoms (45). Common side effects of radiotherapy (e.g. fatigue, pain, depression, and sleeping difficulties) in breast cancer patients (46) might also be related to LUTS (36-38). Therefore, future research should investigate the possible associations among menopausal status, treatments received, and LUTS in breast cancer patients.

Early studies investigating the symptoms or symptom clusters of lung cancer patients seldom addressed LUTS. Gift et al. (5) reported that nocturia was a prevalent symptom $(n=149,68 \%)$ among lung cancer patients. Participants' age (65-89 years of age) is a possible explanation of the high prevalence rate in the Gift et al. study (5) because nocturia is common among older persons (43). Information about the association between lung cancer treatments and LUTS is limited. Common symptoms appearing among cancer patients $(39,41)$ might be a reasonable explanation (36-38) for the high prevalence $(60.0 \%)$ in this study.

Pelvic radiotherapy has negative effects on the lower urinary tract, and severe urinary adverse effects are common after prostate, bladder, and cervical radiotherapy (47). The incidence of lower urinary tract dysfunction after abdominoperineal resection, low anterior resection, and radical hysterectomy is well recognised (48). Aggressive pelvic surgery aimed at reducing the risk of cancer recurrence can also increase genitourinary morbidity. Pelvic surgery may also damage the lower urinary tract and main urogenital nerves (e.g. somatic pudendal nerves). Postoperative scarring, tissue hypoxia resulting from impaired blood flow to the pelvic organs, and consequent bladder wall fibrosis may have negative effect on the lower urinary tract. The partial excision of the vaginal wall, which is sometimes necessary for women with genital system cancer, may impair the anatomy and function of the urinary tract (48).

Chemotherapy, radiotherapy, and surgery are common treatments for patients with colorectal or female genital system cancer. Previous research has shown that long-term UI (38\%) and incomplete emptying (31\%) are prevalent among postoperative rectal cancer patients $(n=785)(49)$, and the prevalence of lower urinary tract dysfunction among gynaecologic 


\begin{tabular}{|c|c|c|c|c|c|}
\hline LUTS & $\begin{array}{l}\text { All }(n=134) \\
\text { Yes, } n(\%)\end{array}$ & $\begin{array}{l}\text { Breast cancer } \\
(\mathrm{n}=39) \\
\text { Yes, } \mathrm{n}(\%)\end{array}$ & $\begin{array}{l}\text { Lung cancer } \\
(\mathrm{n}=30) \\
\text { Yes, } \mathrm{n}(\%)\end{array}$ & $\begin{array}{l}\text { Colorectal cancer } \\
(\mathrm{n}=17) \\
\text { Yes, n (\%) }\end{array}$ & $\begin{array}{l}\text { Female genita } \\
\text { system cancer } \\
(\mathrm{n}=11) \\
\text { Yes, } \mathrm{n}(\%)\end{array}$ \\
\hline Any LUTS & $99(73.9)$ & $31(79.5)$ & $18(60.0)$ & $12(70.6)$ & $9(81.8)$ \\
\hline Storage symptom & $92(68.7)$ & $28(71.8)$ & $16(53.3)$ & $11(64.7)$ & $9(81.8)$ \\
\hline Nocturia ( $\geq 2$ episodes/night) & $70(52.2)$ & $17(43.6)$ & $15(50.0)$ & $10(58.8)$ & $7(63.6)$ \\
\hline Urinary incontinence & $34(25.4)$ & $11(28.2)$ & $4(13.3)$ & $5(29.4)$ & $2(18.2)$ \\
\hline Increased daytime urinary frequency & $33(24.6)$ & $9(23.1)$ & $3(10.0)$ & $3(17.6)$ & $0(0.0)$ \\
\hline Urinary urgency & $24(17.9)$ & $10(25.6)$ & $2(6.7)$ & $2(11.8)$ & $2(18.2)$ \\
\hline Voiding symptom & $34(25.4)$ & $11(28.2)$ & $7(23.3)$ & $4(23.5)$ & $1(9.1)$ \\
\hline Intermittent stream & $26(19.4)$ & $7(17.9)$ & $7(23.3)$ & $3(17.6)$ & $1(9.1)$ \\
\hline Weak urinary stream & $21(15.7)$ & $7(17.9)$ & $3(10.0)$ & $3(17.6)$ & $1(9.1)$ \\
\hline Hesitancy & $5(3.7)$ & $2(5.1)$ & $0(0.0)$ & $1(5.9)$ & $0(0.0)$ \\
\hline Post-micturition symptom & $27(20.1)$ & $11(28.2)$ & $2(6.7)$ & $2(11.8)$ & $3(27.3)$ \\
\hline Incomplete emptying & $27(20.1)$ & $11(28.2)$ & $2(6.7)$ & $2(11.8)$ & $3(27.3)$ \\
\hline
\end{tabular}

cancer survivors is high $(65 \%)(n=108)(50)$. Surgery or radiotherapy-related nerve injury, pelvic floor damage, urinary tract dysfunction, and pelvis anatomy change, and chemotherapy-related oestrogen deficiency in female patients could be possible explanations $(47,48,50)$ for the high prevalence of LUTS among these groups. The sample in this study included a small number of participants with colorectal or female genital system cancer. To examine the possible effects of varied treatments on the lower urinary tract, further research should analyse an adequate sample size for these specific groups.

People with cancer diagnoses seldom discuss LUTS with health care providers because LUTS are not of major concern during treatment. Health care providers, and particularly oncology health care providers, should receive adequate training to screen for LUTS in this population to offer management/treatment recommendations based on available guidelines $(51,52)$. Previous research has reported the beneficial effects of behavioural interventions (e.g. healthy bladder habits or lifestyle modifications) for prevention and treatment of LUTS (53-56). Helpful strategies, such as pelvic floor muscle training, bladder training, establishment of normal voiding intervals, elimination of bladder irritants from the diet, and management of fluid intake and bowel regularity, could be incorporated into patients' daily lives (5356). However, instead of increasing the burden of cancer patients, encouraging the adoption of these self-management practices to relieve LUTS when living with cancer may improve patients' self-efficacy, overall wellness, and HRQL.

\section{Associated factors}

The factors of age, body mass index, obstetric/gynaecological factors, psychological factors (e.g. anxiety or depression), and certain lifestyle factors (e.g. sleep disorders or bladder habit) may be associated with LUTS $(20,36,37)$. Applying the multivariate logistic regression model in this study to the information collected from 77 female participants failed to identify obstetric/gynaecological factors as significant factors associated with LUTS. The inability of this study to identify these common associated factors might result from the uneven distributions of variables (e.g. age, body mass index, and personal habits) and a small sample size. Future research investigating factors associated with LUTS could involve healthy non-cancer control groups. The section entitled 'LUTS in various types of cancer' presents a discussion on the association between radiotherapy and LUTS. Thus, the following discussion focuses on the association between the time since the diagnosis of cancer and LUTS.

Few studies have investigated late adverse effects of cancer treatments, particularly regarding urinary adverse effects $(47,49,57,58)$. Ganz et al. reported that UI symptoms increased among breast cancer survivors $(n=763)$ with initial and follow-up surveys at an average of 3.4 years and 6.3 years after diagnosis (57), respectively. Peeter et al. reported that approximately $40 \%$ of rectal cancer patients ( $n=597$ ) reported UI, and $57 \%$ of them wore pads because of UI (follow-up range: 2.6-7.6 years), regardless of receiving radiotherapy plus surgery or surgery alone (58). Lang et al. followed post-treatment urinary dysfunction for 5 years among rectal 


\begin{tabular}{|c|c|c|c|c|}
\hline HRQL (Norms of Taiwanese ages 12 years and above)* & Participants & Mean \pm SD & $t$ & $\mathbf{p}$ \\
\hline \multirow[t]{3}{*}{ Physical component summary (PCS) } & All $(n=134)$ & $44.8 \pm 11.4$ & -1.74 & 0.087 \\
\hline & With LUTS $(n=99)$ & $43.8 \pm 11.6$ & & \\
\hline & Without LUTS $(n=35)$ & $47.5 \pm 10.8$ & & \\
\hline \multirow[t]{3}{*}{ Physical functioning (92.2 \pm 12.2$)$} & All & $71.2 \pm 25.3$ & -2.78 & $0.007^{+}$ \\
\hline & With LUTS & $68.1 \pm 26.4$ & & \\
\hline & Without LUTS & $79.9 \pm 19.5$ & & \\
\hline \multirow[t]{3}{*}{ Role limitation caused by physical health problems $(83.7 \pm 33.3)$} & All & $42.7 \pm 44.9$ & -2.07 & $0.043^{\dagger}$ \\
\hline & With LUTS & $37.9 \pm 43.6$ & & \\
\hline & Without LUTS & $56.4 \pm 46.3$ & & \\
\hline \multirow[t]{3}{*}{ Bodily pain $(84.8 \pm 19.4)$} & All & $79.6 \pm 22.1$ & -0.14 & 0.890 \\
\hline & With LUTS & $79.4 \pm 22.5$ & & \\
\hline & Without LUTS & $80.0 \pm 21.1$ & & \\
\hline \multirow[t]{3}{*}{ General health $(69.3 \pm 21.3)$} & All & $62.4 \pm 23.6$ & 0.45 & 0.653 \\
\hline & With LUTS & $63.0 \pm 22.5$ & & \\
\hline & Without LUTS & $60.7 \pm 26.7$ & & \\
\hline \multirow[t]{3}{*}{ Mental component summary (MCS) } & All & $47.1 \pm 13.7$ & -0.73 & 0.470 \\
\hline & With LUTS & $46.6 \pm 13.8$ & & \\
\hline & Without LUTS & $48.5 \pm 13.5$ & & \\
\hline \multirow{3}{*}{ Vitality $(68.3 \pm 18.7)$} & All & $57.7 \pm 22.9$ & 0.11 & 0.916 \\
\hline & With LUTS & $57.3 \pm 22.7$ & & \\
\hline & Without LUTS & $57.8 \pm 23.8$ & & \\
\hline \multirow[t]{3}{*}{ Social functioning $(86.8 \pm 17.1)$} & All & $72.8 \pm 24.5$ & -1.49 & 0.142 \\
\hline & With LUTS & $71.1 \pm 25.6$ & & \\
\hline & Without LUTS & $77.5 \pm 20.5$ & & \\
\hline \multirow[t]{3}{*}{ Role limitation caused by emotional problems $(79.4 \pm 36.1)$} & All & $63.9 \pm 45.9$ & -1.50 & 0.139 \\
\hline & With LUTS & $60.6 \pm 47.0$ & & \\
\hline & Without LUTS & $73.3 \pm 41.9$ & & \\
\hline \multirow[t]{3}{*}{ Mental health $(73.0 \pm 16.6)$} & All & $66.7 \pm 18.8$ & 0.48 & 0.632 \\
\hline & With LUTS & $67.2 \pm 17.1$ & & \\
\hline & Without LUTS & $65.1 \pm 23.0$ & & \\
\hline
\end{tabular}

cancer patients $(n=785)$ and reported that UI increased over time (49). Elliott and Malaeb reviewed the long-term adverse effects of pelvic radiotherapy and concluded that urinary adverse effects continue to accrue over time (47).

The results of the current study warrant special concern for late urinary adverse effects after cancer treatment. Only $18(13.4 \%)$ of participants in this study did not receive chemotherapy or radiotherapy. However, a cross-sectional study cannot examine the association between past adjuvant treatment and LUTS, and this topic requires further exploration. Further research conducted in larger, more homogeneous samples and with a longitudinal design might be an appropriate approach.

\section{HRQL, bothers and help-seeking behaviours}

These results are consistent with those reported in previous research $(10,11,14)$. The HRQL scores for partici- pants with LUTS were lower than those for participants without LUTS $(10,11)$, and only a few participants with LUTS seek professional help $(14,15)$. However, 44-47\% of participants with LUTS in this study reported mild to moderate disturbances in daily life and sleep. The differences between cancer patients with and without LUTS were non-significant in $6 \mathrm{HRQL}$ aspects: bodily pain, general health, vitality, social functioning, role limitation caused by emotional problems, and mental health. These non-significant findings might result from the overall poor state of health, poor mental health and wellness among cancer patients (39-41). Because cancer patients may be reluctant to disclose LUTS, and oncology health care providers seldom focus on LUTS, the high prevalence of LUTS and poor help-seeking behaviours shown in this study highlight the need for screening/managing LUTS.

This study has several limitations. First, a cross-sectional design can only suggest an association, and 
cannot demonstrate a causal relationship. Second, the relatively small sample size and sample exclusion (e.g. cognitive impairment) in this study might reduce the generalizability of these results. Third, heterogeneity of the sample regarding cancer types, time since diagnosis, and treatment status might affect the LUTS estimates. Fourth, recall bias cannot be excluded. Some studies have investigated LUTS based on participants' experience during the past 4 weeks/1 month $(7,8,34,35)$, and studies investigating UI in the previous year are also available (59-62). To facilitate comparisons between studies, future studies should collect information during the past 4 weeks/1 month. Fifth, the psychometric assessment for the study questionnaire must be refined. Future studies could use objective examinations (e.g. voiding diary or urodynamic assessments) to validate self-reported LUTS.

\section{Conclusion}

This preliminary study contributes to knowledge about LUTS among cancer patients in Taiwan and increases awareness of this health concern. These results show that LUTS are common among this specific group, suggesting that further research should be conducted with larger, more homogeneous sam- ples. Results show that radiotherapy and the time since the diagnosis of cancer might be linked to LUTS. Further research based on cancer patients' treatment status might be appropriate because LUTS prevalence, severity, and causes can differ at various treatment states. Given the improved survivorship of people diagnosed with different cancers, health care providers should screen for LUTS, deliver adequate management/treatment of LUTS, provide individualised intervention of LUTS, and make appropriate referrals to optimise cancer patients' HRQL.

\section{Acknowledgement}

We greatly appreciate the input of the patients who participated in this study and the financial support of Taipei Medical University Hospital (98TMUTMUH-05-2).

\section{Author contributions}

Concept/design: all authors. Data collection: CIH, ALL, \& YML. Data analysis/interpretation: all authors. Statistics: ALL \& YML. Drafting, critical revisions and approval of article: all authors. Funding secured by: CIH \& YML.

\section{References}

1 Bender CM, Engberg SJ, Donovan HS et al. Symptom clusters in adults with chronic health problems and cancer as a comorbidity. Oncol Nurs Forum 2008; 35: E1-11.

2 Miaskowski C, Dodd M, Lee K. Symptom clusters: the new frontier in symptom management research. J Natl Cancer Inst Monogr 2004; 32: 17-21.

3 Deimling GT, Sterns S, Bowman KF et al. The health of older-adult, long-term cancer survivors. Cancer Nurs 2005; 28: 415-24.

4 Alfano CM, McGregor BA, Kuniyuki A et al. Psychometric properties of a tool for measuring hormone-related symptoms in breast cancer survivors. Psychooncology 2006; 15: 985-1000.

5 Gift AG, Jablonski A, Stommel M et al. Symptom clusters in elderly patients with lung cancer. Oncol Nurs Forum 2001; 31: 202-12.

6 Abrams P, Cardozo L, Fall M et al. The standardisation of terminology of lower urinary tract function: report from the Standardisation Subcommittee of the International Continence Society. Am J Obstet Gynecol 2002; 187: 116-26.

7 Coyne KS, Sexton CC, Thompson CL et al. The prevalence of lower urinary tract symptoms (LUTS) in the USA, the UK and Sweden: results from the epidemiology of LUTS (EpiLUTS) study. BJU Int 2009a; 104: 352-60.

8 Irwin DE, Milsom I, Hunskaar S et al. Populationbased survey of urinary incontinence, overactive bladder, and other lower urinary tract symptoms in five countries: results of the EPIC study. Eur Urol 2006; 50: 1306-15.
9 Lee YS, Lee KS, Jung JH et al. Prevalence of overactive bladder, urinary incontinence, and lower urinary tract symptoms: results of Korean EPIC study. World J Urol 2011; 29: 185-90.

10 Coyne KS, Wein AJ, Tubaro A et al. The burden of lower urinary tract symptoms: evaluating the effect of LUTS on health-related quality of life, anxiety and depression: EpiLUTS. BJU Int 2009b; 103 (Suppl. 3): 4-11.

11 Kupelian V, Wei JT, O'Leary MP et al. Prevalence of lower urinary tract symptoms and effect on quality of life in a racially and ethnically diverse random sample: the Boston Area Community Health (BACH) Survey. Arch Intern Med 2006; 166: 2381-7.

12 Chiaffarino F, Parazzini F, Lavezzari M et al. Impact of urinary incontinence and overactive bladder on quality of life. Eur Urol 2003; 43: 535-8.

13 Helfand BT, McVary KT, Meleth S et al. The relationship between lower urinary tract symptom severity and sleep disturbance in the CAMUS trial. J Urol 2011; 185: 2223-8.

14 Apostolidis A, Kirana PS, Chiu G et al. Gender and age differences in the perception of bother and health care seeking for lower urinary tract symptoms: results from the hospitalized and outpatients' profile and expectations study. Eur Urol 2009; 56: 937-47.

15 Irwin DE, Milsom I, Kopp Z et al. Symptom bother and health care-seeking behavior among individuals with overactive bladder. Eur Urol 2008; 53: 1029-37.

16 Davidson JR, MacLean AW, Brundage MD et al. Sleep disturbance in cancer patients. Soc Sci Med 2002; 54: 1309-21.
17 Fiorentino L, Ancoli-Israel S. Sleep dysfunction in patients with cancer. Curr Treat Options Neurol 2007; 9: 337-46.

18 Liao YM, Dougherty MC, Boyington AR et al. Developing and validating a Chinese instrument to measure lower urinary tract symptoms among employed women in Taiwan. Nurs Outlook 2006; 54: 353-61.

19 Lynn MR. Determination and quantification of content validity. Nurs Res 1986; 35: 382-5.

20 Liao YM, Dougherty MC, Biemer PP et al. Factors related to lower urinary tract symptoms among a sample of employed women in Taipei. Neurourol Urodyn 2008; 27: 52-9.

21 American Joint Committee on Cancer. What is cancer staging? http://www.cancerstaging.org/mission/whatis.html. (accessed July 2012).

22 Abrams P, Artibani W, Cardozo L et al. Reviewing the ICS 2002 terminology report: the ongoing debate. Neurourol Urodyn 2009; 28: 287.

23 Liao YM, Dougherty MC, Biemer PP et al. Prevalence of lower urinary tract symptoms among female elementary school teachers in Taipei. Int Urogynecol J Pelvic Floor Dysfunct 2007; 18: 115161.

24 Ware JE, Snow KK, Kosinski M et al. SF-36 Health Survey: Manual and Interpretation Guide. Boston, MA: The Health Institute, New England Medical Center, 1993.

25 Ware JE, Kosinski M. SF-36 Physical and Mental Health Summary Scales: A Manual for Users of Version 1, 2nd edn. Lincoln, RI: Quality Metric Inc., 2001. 
26 Fuh JL, Wang SJ, Lu SR et al. Psychometric evaluation of a Chinese (Taiwanese) version of the SF-36 health survey amongst middle-aged women from a rural community. Qual Life Res 2000; 9: 675-83.

$27 \mathrm{Lu}$ JF, Tseng HM, Tsai YJ. Assessment of healthrelated quality of life in Taiwan (I): development and psychometric testing of SF-36 Taiwan version. Taiwan J Public Health 2003; 22: 501-11.

28 Tseng HM, Lu JF, Tsai YJ. Assessment of healthrelated quality of life in Taiwan (II): norming and validation of the SF-36 Taiwan version. Taiwan J Public Health 2003; 22: 512-8.

29 Hosmer DW, Lemeshow S. Applied Logistic Regression, 2nd edn. New York: John Wiley \& Sons, Inc, 2000.

30 Martin SA, Haren MT, Marshall VR et al. Prevalence and factors associated with uncomplicated storage and voiding lower urinary tract symptoms in community-dwelling Australian men. World $J$ Urol 2011; 29: 179-84.

31 Teleman P, Lidfeldt J, Nerbrand C et al. Lower urinary tract symptoms in middle-aged women prevalence and attitude towards mild urinary incontinence: a community-based population study. Acta Obstet Gynecol Scand 2005; 84: 110812.

32 Nørby B, Nordling J, Mortensen S. Lower urinary tract symptoms in the Danish population: a population-based study of symptom prevalence, healthcare seeking behavior and prevalence of treatment in elderly males and females. Eur Urol 2005; 47: 817-23.

33 Wehrberger C, Madersbacher S, Jungwirth S et al. Lower urinary tract symptoms and urinary incontinence in a geriatric cohort - a population-based analysis. BJU Int 2012; 110: 1516-21.

34 Homma Y, Yamaguchi O, Hayashi $\mathrm{K}$ et al. Epidemiologic survey of lower urinary tract symptoms in Japan. Urology 2006; 68: 560-4.

35 Perry S, Shaw C, Assassa P et al. An epidemiological study to establish the prevalence of urinary symptoms and felt need in the community: the Leicestershire MRC Incontinence Study. Leicestershire MRC Incontinence Study Team. I Public Health Med 2000; 22: 427-34.

36 Coyne KS, Kaplan SA, Chapple CR et al. Risk factors and comorbid conditions associated with lower urinary tract symptoms: EpiLUTS. BJU Int 2009; 103 (Suppl. 3): 24-32.

37 Litman HJ, Steers WD, Wei JT et al. Relationship of lifestyle and clinical factors to lower urinary tract symptoms: results from Boston Area Community Health survey. Urology 2007; 70: 916-21.

38 Klausner AP, Steers WD. Corticotropin releasing factor: a mediator of emotional influences on bladder function. J Urol 2004; 172: 2570-3.

39 Linden W, Vodermaier A, Mackenzie R et al. Anxiety and depression after cancer diagnosis: prevalence rates by cancer type, gender, and age. J Affect Disord 2012; 141: 343-51.

40 Marcus DA. Epidemiology of cancer pain. Curr Pain Headache Rep 2011; 15: 231-4.

41 Savard J, Ivers H, Villa J et al. Natural course of insomnia comorbid with cancer: an 18-month longitudinal study. J Clin Oncol 2011; 29: 3580-6.

42 van Kerrebroeck P, Abrams P, Chaikin D et al. The standardisation of terminology in nocturia: report from the Standardisation Sub-committee of the International Continence Society. Neurourol Urodyn 2001; 21: 179-83.

43 Bosch JL, Weiss JP. The prevalence and causes of nocturia. J Urol 2010; 184: 440-6.

44 Donovan KA, Boyington AR, Ismail-Khan $\mathrm{R}$ et al. Urinary symptoms in breast cancer: a systematic review. Cancer 2012; 118: 582-93.

45 Ganz PA, Rowland JH, Meyerowitz BE et al. Impact of different adjuvant therapy strategies on quality of life in breast cancer survivors. Resent Results Cancer Res 1998; 152: 396-411.

46 Sjövall K, Strömbeck G, Löfgren A et al. Adjuvant radiotherapy of women with breast cancer - information, support and side-effects. Eur J Oncol Nurs 2010; 14: 147-53.

47 Elliott SP, Malaeb BS. Long-term urinary adverse effects of pelvic radiotherapy. World J Urol 2011; 29: 35-41.

48 Bosch JL, Norton P, Jones JS. Should we screen for and treat lower urinary tract dysfunction after major pelvic surgery? ICI-RS 2011. Neurourol Urodyn 2012; 31: 327-9.

49 Lange MM, Maas CP, Marijnen CA et al. Urinary dysfunction after rectal cancer treatment is mainly caused by surgery. Br J Surg 2008; 95: 1020-8.

50 Manchana T. Long-term lower urinary tract dysfunction in gynecologic cancer survivors. Asian Pac J Cancer Prev 2011; 12: 285-8.

51 Trinkaus M, Chin S, Wolfman W et al. Should urogenital atrophy in breast cancer survivors be treated with topical estrogens? Oncologist 2008; 13: 222-31.

52 Zibecchi L, Greendale GA, Ganz PA. Comprehensive menopausal assessment: an approach to man- aging vasomotor and urogenital symptoms in breast cancer survivors. Oncol Nurs Forum 2003 30: 393-407.

53 Diokno AC, Sampselle CM, Herzog AR et al. Prevention of urinary incontinence by behavioral modification program: a randomized, controlled trial among older women in the community. $J$ Urol 2004; 171: 1165-71.

54 Dumoulin C, Hay-Smith J. Pelvic floor muscle training versus no treatment, or inactive control treatments, for urinary incontinence in women. Cochrane Database Syst Rev 2010; 1: CD005654.

55 Sievert KD, Amend B, Toomey PA et al. Can we prevent incontinence? ICI-RS 2011. Neurourol Urodyn 2012; 31: 390-9.

56 Wyman JF, Burgio KL, Newman DK. Practical aspects of lifestyle modifications and behavioural interventions in the treatment of overactive bladder and urgency urinary incontinence. Int J Clin Pract 2009; 63: 1177-91.

57 Ganz PA, Desmond KA, Leedham B et al. Quality of life in long-term, disease-free survivors of breast cancer: a follow-up study. J Natl Cancer Inst 2002; 94: 39-49.

58 Peeters KC, van de Velde CJ, Leer JW et al. Late side effects of short-course preoperative radiotherapy combined with total mesorectal excision for rectal cancer: increased bowel dysfunction in irradiated patients - a Dutch colorectal cancer group study. J Clin Oncol 2005; 23: 6199-206.

59 Danforth KN, Townsend MK, Lifford K et al. Risk factors for urinary incontinence among middleaged women. Am J Obstet Gynecol 2006; 194: 33945.

60 Tennstedt SL, Link CL, Steers WD et al. Prevalence of and risk factors for urine leakage in a racially and ethnically diverse population of adults: the Boston Area Community Health (BACH) Survey. Am J Epidemiol 2008; 167: 390-9.

61 Thom DH, van den Eeden SK, Ragins AI et al. Differences in prevalence of urinary incontinence by race/ethnicity. J Urol 2006; 175: 259-64.

62 Townsend MK, Curhan GC, Resnick NM et al. The incidence of urinary incontinence across Asian, black, and white women in the United States. Am J Obstet Gynecol 2010; 202: 378. el-e7.

Paper received September 2012, accepted January 2013 